\title{
Sarcoidosis and sacroiliitis, a case report
}

\author{
Laisa Socorro Briongos-Figuero • Ángela Ruiz-de-Temiño • \\ José Luis Pérez-Castrillón
}

Received: 24 March 2011 / Accepted: 21 August 2011

(C) Springer-Verlag 2011

\begin{abstract}
Sarcoidosis is a multisystem disorder of unknown etiology characterized by the presence of non-caseating granulomas in the organs affected. Sarcoid arthropathy is a rare manifestation, and sacroiliitis is an unusual first manifestation of the disorder
\end{abstract}

Keywords Sarcoidosis - Sarcoidosis/complications* . Sarcoidosis*/diagnosis · Bilateral sacroiliitis

Sarcoidosis is a multisystem granulomatous disorder of unknown etiology, and incidence and prevalence vary among different geographic areas being 3-4 times more common in blacks. The disease mainly affects young adults, and the organ most commonly involved is the respiratory tract, appearing joint involvement in 15-25\% of patients with sarcoidosis [1]. Sacroiliitis is an inflammatory joint disease and its association with sarcoidosis is very rare. Only few cases have been described in the literature, even less if sacroiliitis is the first manifestation of sarcoidosis $[2,3]$.

We report the case of a 23-year-old man without relevant previous medical history. He was admitted to our Internal Medicine Service with complaints of symmetrical low back pain in both sacroiliac joints and ankles with swelling and difficulty for walk during 1 week. He also reported associated pleuritic pain in right hemithorax, cough with white sputum expectoration during the previous days. Physical examination revealed the presence of lateral cervical lymph

L. S. Briongos-Figuero $(\bowtie)$ · Á. Ruiz-de-Temiño ·

J. L. Pérez-Castrillón

Internal Medicine Department, Rio Hortega University Hospital, C/Dulzaina 2, 47012 Valladolid, Spain

e-mail: laisadoc@hotmail.com painful nodes and swelling in both ankles with pain and flush without the loss of motion. Laboratory findings showed 14100 leukocytes per $\mathrm{ml}$ (neutrophils $74 \%$ and lymphocytes 15\%) and serum C-reactive protein $99 \mathrm{mg} / \mathrm{dl}$, while red-cell count and platelet count were normal. Serologic investigation showed negative results for viral hepatitis A, B and C, HIV, cytomegalovirus, toxoplasma, brucella, Chlamydia pneumoniae, Coxiella burnetii, Legionella pneumophila and Treponema. A chest radiograph showed prominent hilum with a bilateral interstitial pattern. To complete the study, we decided to take a new blood analysis that showed angiotensin-converting enzyme (ACE) of $64.6 \mathrm{U} / 1$ with elevated calcium in the 24-hour urine sample. HLA B27 and interferon gamma were also negative. Chest computed tomography (CT) showed adenopathies in right paratracheal thymic region, subcarinal and bilateral hilar and also parenchymal involvement with nodular confluent opacities and patchy distribution. Sacroiliac joint CT highlights the existence of interarticular sclerosis and irregularities of both joints compatible with bilaterally spondylitis (sacroiliitis). Bronchoscopy examination was normal, and the bronchoalveolar lavage was negative for microorganism, and flow cytometry showed a CD4/CD8 ratio of 80:20 compatible with sarcoidosis. Transbronchial biopsy revealed non-caseating granulomatosis compatible with sarcoidosis. The case was diagnosed to be a co-occurrence of sarcoidosis with pulmonary involvement and sacroiliitis. Anti-inflammatories and corticosteroids (oral prednisone) at doses of $1 \mathrm{mg} / \mathrm{Kg}$ per day were ordered, showing good clinical response during hospital admission and subsequent follow-up of outpatients.

Sarcoidosis can mimic rheumatic diseases and even coexist with any of them. The most common form of joint involvement in sarcoidosis is acute, migratory, polyarticular and symmetrical arthritis. Chronic form is less common 
and affects multiple joints in a recurrent and erosive way. Sacroiliitis is an inflammatory arthropathy and behaves as a rare manifestation of sarcoidosis having been detected a prevalence around $6 \%$, higher than in the general population $(1.9 \%)[4,5]$. There are few cases in scientific literature of sacroiliitis associated with sarcoidosis, being still more rare the sacroiliac involvement as initial manifestation of the disease [2, 5-9]. The diagnosis is established by the clinical and radiological findings and may rely on the detection of non-caseating granulomas in a sinoval sample. Treatment involves the use of steroids. In a recent study, Erb et al. [4]. describe the association between these two conditions and find that the presence of HLA-B27 increases the risk of spondyloarthropathy. In our patient, it is noteworthy that the first manifestation of sarcoid disease is the axial skeleton involvement bilaterally, after ruling out other etiologies as a cause of the disorder.

In conclusion, the diagnosis of sarcoidosis in patients with sacroiliac involvement is a challenge for clinicians and involves a high degree of suspicion to detect the coexistence of both diseases.

Conflict of interest The authors declare that they have no conflict of interest.

\section{References}

1. Pettersson T (1997) Rheumatic features of sarcoidosis. Curr Opin Rheumatol 9:62-67

2. Kotter I, Durk H, Saal JG (1995) Sacroiliitis in sarcoidosis: case reports and review of the literature. Clin Rheumatol 14:695-700

3. Visser H, Vos K, Zanelli E, Verduyn W, Schreuder GM, Speyer I, Breedveld FC, Hazes JM (2002) Sarcoid arthritis: clinical characteristics, diagnostic aspects, and risk factors. Ann Rheum Dis 61:499-504

4. Erb N, Cushley MJ, Kassimos DG, Shave RM, Kitas GD (2005) An assessment of back pain and the prevalence of sacroiliitis in sarcoidosis. Chest 127:192-196

5. Sezer I, Melikoglu MA, Cay HF, Kocabas H, Kacar C (2008) A co-occurrence of sarcoidosis and ankylosing spondylitis: a case report. Rheumatol Int 28:605-607

6. Kremer P, Gallinet E, Benmansour A, Despaux J, Toussirot E, Wendling D (1996) Sarcoidosis and spondyloarthropathy. Three case-reports. Rev Rhum Engl Ed 63:405-411

7. Binicier O, Sari I, Sen G, Onen F, Akkoc N, Manisali M, Akar S (2009) Axial sarcoidosis mimicking radiographic sacroiliitis. Rheumatol Int 29:343-345

8. Kirkham B, Jobanputra P (1988) Sarcoidosis and spondarthritis. Br J Rheumatol 27:241

9. Stucki G, von Felten A, Speich R, Michel BA (1992) Ankylosing spondylitis and sarcoidosis-coincidence or association? Case report and review of the literature. Clin Rheumatol 11:436-439 